\title{
Obstructive sleep apnoea accelerates FEV 1 decline in asthmatic patients
}

\author{
Tsai-Yu Wang ${ }^{1}$, Yu-Lun Lo1', Shu-Min Lin ${ }^{1}$, Chien-Da Huang ${ }^{1}$, Fu-Tasi Chung ${ }^{1,2}$, Horng-Chyuan Lin', \\ Chun-Hua Wang ${ }^{1}$ and Han-Pin Kuo ${ }^{1 *}$
}

\begin{abstract}
Background: Although the prevalence of both obstructive sleep apnoea (OSA) and asthma are both increasing, little is known about the impact of OSA on the natural history of lung function in asthmatic patients.

Methods: A total of 466 patients from our sleep laboratory were retrospectively enrolled. Of them, 77 patients (16.5\%) had asthma with regular follow-up for more than 5 years. Their clinical characteristics, pulmonary function, emergency room visits, and results of polysomnography results were analysed.

Results: The patients were divided into three groups according to the severity of the apnoea-hypopnea index $(\mathrm{AHI})$. The decline in $\mathrm{FEV}_{1}$ among asthma patients with severe OSA (AHI > 30/h) was $72.4 \pm 61.7 \mathrm{ml} /$ year $(\mathrm{N}=34)$, as compared to $41.9 \pm 45.3 \mathrm{ml} /$ year $(N=33, P=0.020)$ in those with mild to moderate OSA $(5<\mathrm{AHI} \leq 30)$ and $24.3 \pm$ $27.5 \mathrm{ml} /$ year $(N=10, P=0.016)$ in those without OSA (AHI $\leq 5)$. For those patients with severe OSA, the decline of FEV ${ }_{1}$ significantly decreased after continuous positive airway pressure (CPAP) treatment. After multivariate stepwise linear regression analysis, only $\mathrm{AHI}$ was remained independent factor for the decline of $F E V_{1}$ decline.
\end{abstract}

Conclusions: Asthmatic patients with OSA had substantially greater declines in FEV ${ }_{1}$ than those without OSA. Moreover, CPAP treatment alleviated the decline of $\mathrm{FEV}_{1}$ in asthma patients with severe OSA.

Keywords: Obstructive sleep apnoea, Pulmonary function, asthma

\section{Background}

Although both asthma and obstructive sleep apnoea (OSA) are common diseases with increasing prevalence, the impact of OSA on the natural history of pulmonary function decline has not been well described. Increased mortality and morbidities in those with declining pulmonary function have been revealed in previous studies on asthmatic patients selected from the general population [1-3]. These highlight the role of the decline rate in pulmonary function in asthmatic patients. Factors associated with such rapid decline of pulmonary function include age, sex, smoking, acute exacerbation, obesity, and hypoxia [4-6]. While obesity is associated with OSA, hypoxia during sleep is also a cardinal feature of OSA [7]. As previous reports, both obesity and hypoxia aggravated the decline of pulmonary function, which implies

\footnotetext{
* Correspondence: q8828@ms11.hinet.net

${ }^{1}$ Pulmonary Disease Research Centre, Department of Thoracic Medicine, Chang Gung Memorial Hospital, Chang Gung University, School of Medicine, 199 Tun-Hwa N. Rd., Taipei, Taiwan

Full list of author information is available at the end of the article
}

the role of OSA in pulmonary function decline of asthmatic patients. In addition, the impact of OSA on asthma control such as symptoms, peak flow rate, acute exacerbation and quality of life are well documented [7-11]. Moreover, acute exacerbation which is related to the decline of pulmonary function in asthmatic patients can be reversed by continuous positive airway pressure (CPAP) [10, 12, 13]. Therefore, we hypothesize that OSA is an independent factor associated with the decline in pulmonary function in patients with asthma, and CPAP treatment prevents the decline by improving nocturnal hypoxia and frequency of acute exacerbation.

Although previous studies show that CPAP treatment cannot improve pulmonary function in asthmatic patients with OSA $[10,12]$, the impact of OSA on pulmonary function decline may require long-term longitudinal follow-up studies. In this study, the aim of this study was to evaluate the annual pulmonary function decline in asthmatic patients with OSA in comparison to those without in a sleep laboratory-based population, and to examine 
the clinical efficacy of CPAP treatment. The analyses were mainly based on asthmatic patients with more than 5 years of follow-up in Chang Gung Memorial Hospital, Linko and Taipei, Taiwan.

\section{Methods}

\section{Study population}

From January to August 2011, asthmatic patients were retrospectively recruited from the sleep laboratory of Chang Gung Memorial Hospital, a tertiary hospital in Taiwan. Patients were excluded if they were not regularly followed-up more than 5 years. The Chang Gung Medical Foundation Institutional Review Board (103-1609B) approved the study and waived the requirement for informed consent due to the retrospective nature of this study.

\section{Study design}

Each patient's medical records were reviewed to collect the clinical characteristics and laboratory results. Information, including results of pulmonary function, polysomnography, and emergency department (ER) visits due to exacerbations of asthma and CPAP compliance, were analysed. For asthmatic patients with severe OSA, another 2year follow-up for pulmonary function test were also collected for further analysis. Pulmonary function such as $\mathrm{FEV}_{1}$ and FVC were measured by an electronic spirometer, which was calibrated daily using a 1-litre syringe. For the correct performance of the procedure as standard requirement, the difference between at least two $\mathrm{FEV}_{1}$ measurements was $<5 \%$. In addition, the highest value of $\mathrm{FEV}_{1}$ was chosen for the analyses.

\section{Definitions}

All patients reported a personal history of asthma such as episodic breathlessness, cough, wheezing, chest tightness, and seasonal variability. Asthma was confirmed by clinical and functional assessment as defined by the American Thoracic Society criteria [14]. Airway reversibility was defined as $12 \%$ and $200 \mathrm{ml}$ increase in $\mathrm{FEV}_{1}$ or average daily diurnal peak flow variability is more than $10 \%$ [15]. Regular follow-up was defined as a return to outpatient clinics of at least every 3 months with pulmonary function test at least every 6 months. Emergency room visits were considered when patients went to the ER due to asthma exacerbation. A maximum of one ER visit every 3 months was counted. From the charts, the patients reported themselves as current smokers, exsmokers, or never-smokers, but both ex-smokers and never-smokers were defined as non-smokers.

\section{Polysomnography and CPAP titration}

Polysomnography (Alice 5, Respironics) was performed on all patients using standard techniques. Sleep stages and arousals were scored according to the AASM criteria
[16]. Established criteria were used to score respiratory events such as hypopnea, obstructive apnoea, central apnoea, mixed type apnoea, and Cheyne-Stokes respiration $[17,18]$. Apnoea was defined as oronasal flow cessation for more than $10 \mathrm{~s}$. Hypopnea was defined as a 50\% reduction in oronasal flow or a $30 \%$ reduction, followed by arousal or more than 3\% decrease in $\mathrm{SaO} 2$ [17].

Based on the polysomnography results, OSA was defined as an apnoea-hypopnea index (AHI) $>5$ per hour, of which $\geq 80 \%$ were obstructive. Mild-to-moderate OSA was defined as AHI $>5$ per hour and AHI $\leq 30$ per hour. Severe OSA was defined as AHI $>30$ per hour. To determine optimal pressure, CPAP titration was performed according to standard guidelines [19]. Good CPAP compliance was defined as $>4 \mathrm{~h}$ per day for $>5$ days per week.

\section{Statistical analysis}

Data were expressed as mean \pm SEM (standard error of the mean). One-way ANOVA was used for comparison of continuous variables among the three groups, while the Kruskal-Wallis test was used for non-normal distributions. Categorical variables were compared by $x 2$ or Fisher's exact test. The Pearson product correlation coefficient was used to examine correlations between variables and the decline in $\mathrm{FEV}_{1}$. Multivariate stepwise linear regression analysis was used to determine independent factors affecting the decline in $\mathrm{FEV}_{1}$. Statistical significance was set at $p<0.05$. Analysis conducted using the SPSS (version 13.0; SPSS; Chicago, IL) statistical software.

\section{Results}

Subject characteristics and polysomnography results

There were 466 patients with polysomnography results from the sleep laboratory, including 77 (16.5\%) with asthma and regular follow-up more than 5 years. Their baseline demographics and clinical characteristics (Table 1) revealed that the mean age of asthmatic patients without OSA, those with mild-to-moderate OSA, and those with severe OSA was 49.0 years, 60.0 years, and 62.9 years, respectively. The other characteristics were similar among the three groups, including the percentage of males, and baseline pulmonary function such as $\mathrm{FEV}_{1}$ and FVC in the first year. From the results of polysomnography (Table 2), AHI, ODI, average $\mathrm{SaO} 2$, and lowest $\mathrm{SaO} 2$, as well as sleep architecture like slow-wave sleep stage (N3) and rapid eye movement (REM) stage, were significantly worse in asthmatic patients with severe OSA.

\section{Annual decline of $\mathrm{FEV}_{1}$ in asthmatic patients with different OSA severities}

The most important finding of the present study was that the annual decline in $\mathrm{FEV}_{1}$ of asthmatic patients with severe OSA was significantly accelerated compared to those of patients with mild-to-moderate OSA and 
Table 1 Patient characteristics

\begin{tabular}{|c|c|c|c|c|}
\hline \multirow[t]{2}{*}{ Characteristics } & \multirow{2}{*}{$\begin{array}{l}\text { No OSA } \\
n=10\end{array}$} & \multirow{2}{*}{$\begin{array}{l}\text { Mild-to-Moderate OSA } \\
n=33\end{array}$} & \multirow{2}{*}{$\begin{array}{l}\text { Severe OSA } \\
n=34\end{array}$} & \multirow[t]{2}{*}{$p$ value } \\
\hline & & & & \\
\hline Age & $49.0 \pm 13.6$ & $60.0 \pm 13.3$ & $62.9 \pm 12.7$ & 0.021 \\
\hline Male, n (\%) & $6(60)$ & $25(75.8)$ & $20(58.8)$ & 0.348 \\
\hline $\mathrm{BMI}$ & $23.4 \pm 4.0$ & $24.8 \pm 4.3$ & $29.7 \pm 4.7$ & 0.001 \\
\hline Current Smoker, n (\%) & $2(20.0)$ & $10(30.3)$ & $12(35.3)$ & 0.653 \\
\hline \multicolumn{5}{|l|}{ Pulmonary function Test (1st year) } \\
\hline $\mathrm{FEV}_{1} / \mathrm{FVC}$ & $71.9 \pm 13.2$ & $73.2 \pm 18.9$ & $79.1 \pm 13.9$ & 0.078 \\
\hline $\mathrm{FEV}_{1}$, Litre & $2.12 \pm 0.44$ & $1.75 \pm 0.82$ & $1.91 \pm 0.80$ & 0.400 \\
\hline $\mathrm{FEV}_{1}(\%$ predicted $)$ & $68.6 \pm 15.9$ & $65.3 \pm 24.6$ & $77.1 \pm 25.3$ & 0.132 \\
\hline FVC, Litre & $2.94 \pm 0.42$ & $2.39 \pm 0.83$ & $2.41 \pm 0.84$ & 0.096 \\
\hline Decline of $\mathrm{FEV}_{1} /$ year, (\% from baseline) & $1.3 \pm 1.3$ & $3.1 \pm 3.3$ & $4.3 \pm 3.4$ & 0.024 \\
\hline Decline of $\mathrm{FEV}_{1} /$ year, (\% predicted) & $0.0 \pm 1.1$ & $1.0 \pm 1.9$ & $2.3 \pm 3.0$ & 0.027 \\
\hline Decline of $\mathrm{FEV}_{1} /$ year $(\mathrm{mL})$ & $24.3 \pm 27.5$ & $41.9 \pm 45.3$ & $72.4 \pm 61.7$ & 0.046 \\
\hline Decline of FVC/year, (\% from baseline) & $1.1 \pm 3.6$ & $1.4 \pm 3.4$ & $2.6 \pm 3.6$ & 0.499 \\
\hline Decline of FVC/year, (\% predicted) & $0.6 \pm 3.4$ & $0.8 \pm 2.6$ & $1.6 \pm 2.9$ & 0.608 \\
\hline Decline of FVC/year, (mL) & $32.5 \pm 111.1$ & $39.9 \pm 84.4$ & $54.9 \pm 76.1$ & 0.735 \\
\hline ER visit, n/year & $0.11 \pm 0.14$ & $0.48 \pm 0.63$ & $0.52 \pm 0.62$ & 0.256 \\
\hline \multicolumn{5}{|l|}{ Medication } \\
\hline Inhaled glucocorticoid & $9(90)$ & $33(100)$ & $31(91.2)$ & 0.208 \\
\hline Inhaled long-acting beta-agonist & $6(60)$ & $25(75.8)$ & $30(88.2)$ & 0.128 \\
\hline Leukotriene antagonist & $1(10)$ & $10(30.3)$ & $21(61.8)$ & 0.003 \\
\hline
\end{tabular}

Data are presented as mean \pm SEM, or number (percentage)

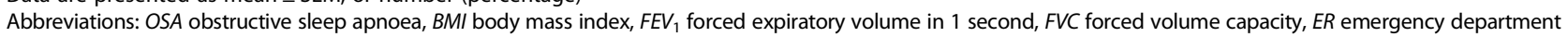

Table 2 Polysomnography results

\begin{tabular}{|c|c|c|c|c|}
\hline \multirow[t]{2}{*}{ Characteristics } & No OSA & Mild-Moderate OSA & Severe OSA & \multirow[t]{2}{*}{$p$ value } \\
\hline & $n=10$ & $n=33$ & $n=34$ & \\
\hline Total sleep time (minutes) & $288.2 \pm 88.2$ & $268.3 \pm 80.7$ & $253.8 \pm 74.6$ & 0.207 \\
\hline Sleep efficiency (\%) & $76.1 \pm 22.9$ & $75.8 \pm 16.1$ & $72.1 \pm 18.0$ & 0.506 \\
\hline $\mathrm{AHI}$ event. $\mathrm{h}^{-1}$ & $2.4 \pm 1.5$ & $16.2 \pm 6.6$ & $61.4 \pm 20.0$ & 0.001 \\
\hline ODI event. $\mathrm{h}^{-1}$ & $1.7 \pm 1.7$ & $14.5 \pm 6.1$ & $52.1 \pm 22.8$ & 0.001 \\
\hline Average $\mathrm{SaO}_{2}(\%)$ & $95.0 \pm 1.3$ & $93.1 \pm 3.0$ & $91.4 \pm 3.3$ & 0.001 \\
\hline Lowest $\mathrm{SaO}_{2}(\%)$ & $88.2 \pm 6.0$ & $82.2 \pm 5.5$ & $74.7 \pm 9.7$ & 0.001 \\
\hline $\mathrm{SaO} 2<90 \%(\%)$ & $0 \pm 0$ & $9.1 \pm 18.2$ & $20.5 \pm 25.9$ & 0.001 \\
\hline $\mathrm{SaO} 2<80 \%(\%)$ & $0 \pm 0$ & $0.2 \pm 0.4$ & $3.3 \pm 5.2$ & 0.021 \\
\hline Wake \% & $13.9 \pm 8.1$ & $22.4 \pm 13.7$ & $22.7 \pm 17.8$ & 0.226 \\
\hline N1 \% & $20.8 \pm 11.0$ & $16.5 \pm 11.0$ & $22.3 \pm 10.7$ & 0.423 \\
\hline N2 \% & $27.6 \pm 11.5$ & $28.8 \pm 11.2$ & $34.1 \pm 14.1$ & 0.125 \\
\hline N3 \% & $23.6 \pm 8.4$ & $22.1 \pm 10.8$ & $13.4 \pm 9.8$ & 0.001 \\
\hline REM \% & $14.1 \pm 3.4$ & $10.3 \pm 8.5$ & $7.4 \pm 5.9$ & 0.013 \\
\hline
\end{tabular}

Data are presented as mean \pm SEM, or number (percentage)

Abbreviations: OSA obstructive sleep apnoea, $A H I$ apnoea-hypopnoea index, ODI oxygen desaturation index, SWS slow wave sleep, REM rapid eye movement, CPAP continuous positive airway pressure 
those of patients without OSA $(72.4 \pm 61.7$ milli-litre vs. $41.9 \pm 45.3$ milli-litre vs. $24.3 \pm 27.5$ milli-litre, $p=0.046$ ) (Fig. 1). In contrast, the annual decline in FVC was not significantly different among the three groups.

In terms of possible aetiologies responsible for the annual decline of $\mathrm{FEV}_{1}$, \% from baseline, univariate analysis (Tables 3) revealed that age, AHI, ODI, and ER visit were significantly associated with the annual decline in $\mathrm{FEV}_{1}$, \% predicted (Fig. 2). Although BMI was significantly different between the three groups, it was not significantly associated with the annual decline in $\mathrm{FEV}_{1}, \%$ from baseline. After multivariate stepwise linear analysis, only AHI remained independent factor associated with the annual decline in $\mathrm{FEV}_{1}, \%$ predicted (Table 4).

\section{CPAP treatment alleviated the rapid decline of $\mathrm{FEV}_{1}$ in asthmatic patients with severe OSA}

Thirty-eight percent (13/34) of asthmatic patients with severe OSA treated with CPAP had good compliance. In the annual decline in $\mathrm{FEV}_{1}$ before and after CPAP treatment (Fig. 3), after adequate CPAP treatment for the next 2 years, the annual decline in $\mathrm{FEV}_{1}$ was $41.2 \pm$ $36.1 \mathrm{~mL}$, which was significantly lower than that before CPAP treatment $(69.4 \pm 66.4 \mathrm{~mL}, p=0.028)$. The frequency of ER visits were also decreased after CPAP treatment from $0.35 \pm 0.52$ per year to $0.35 \pm 0.52$ per year but there was just trend $(P=0.058)$. The average CPAP pressure was $8.9 \pm 4.2 \mathrm{cmH}_{2} \mathrm{O}$ and the average time of CPAP use was $6.4 \mathrm{~h}$ per night.

\section{Discussion}

The present study demonstrates that asthmatic patients with obstructive sleep apnoea have a greater decline in $\mathrm{FEV}_{1}$ over time than those without OSA. Although age,

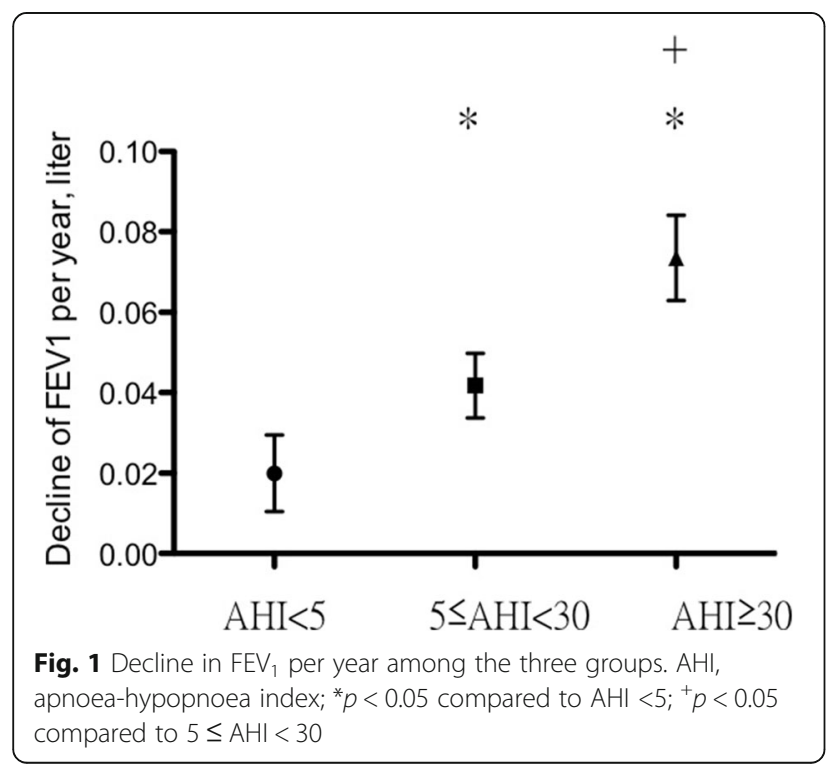

Table 3 Univariate analysis of variables associated with average decline of $\mathrm{FEV}_{1}, \%$ predicted

\begin{tabular}{llclc}
\hline Parameter & beta & Standard error & $95 \% \mathrm{Cl}$ & $p$ value \\
\hline Age & -0.053 & 0.020 & -0.093 to -0.012 & 0.011 \\
ESS & -0.280 & 0.085 & -0.323 to 0.021 & 0.084 \\
BMI & -0.077 & 0.056 & -0.189 to 0.036 & 0.178 \\
Current smoke & -1.173 & 0.599 & -2.367 to 0.021 & 0.054 \\
AHI & -0.033 & 0.009 & -0.052 to -0.014 & 0.001 \\
ODI & -0.035 & 0.010 & -0.056 to -0.015 & 0.001 \\
SaO2 <90\% (\%) & -0.014 & 0.015 & -0.043 to 0.015 & 0.347 \\
SaO2 < 80\% (\%) & -0.091 & 0.094 & -0.280 to 0.097 & 0.336 \\
ICS & -0.091 & 1.646 & -4.581 to 1.977 & 0.432 \\
ER visit, n/year & -0.941 & 0.470 & -1.877 to -0.005 & 0.049 \\
\hline
\end{tabular}

Abbreviations: ESS epworth sleepiness scores, BMI body mass index, $A H I$ apnoeahypopnoea index, ODI oxygen desaturation index, ICS inhaled corticosteroid, $E R$ emergency department

AHI, ODI, and ER visits are significant factors associated with a greater decline in $\mathrm{FEV}_{1}$ under univariate analysis, only AHI is an independent factor in multivariate analysis. Moreover, CPAP treatment alleviates the accelerated decline in $\mathrm{FEV}_{1}$ in asthmatic patients with severe OSA, which further consolidates the role of OSA in the decline in $\mathrm{FEV}_{1}$ among asthmatic patients.

The natural history of $\mathrm{FEV}_{1}$ decline in asthmatic patients has been reported to be $38-40.9 \mathrm{ml} /$ year $[6,20-22]$. Factors associated with the decline in pulmonary function are age, sex, smoking, acute exacerbation, obesity, and hypoxia [4-6]. Furthermore, OSA with obesity and hypoxia as central features, significantly contribute to asthma control and exacerbation. Thus, it is not surprising that CPAP treatment of up to 2 years for asthmatic patients with severe OSA is beneficial not only in terms of quality of life and in alleviating asthma symptoms but also in reducing $\mathrm{FEV}_{1}$ decline.

Frequent symptoms and exacerbations have been reported to be associated with an excess decline in lung

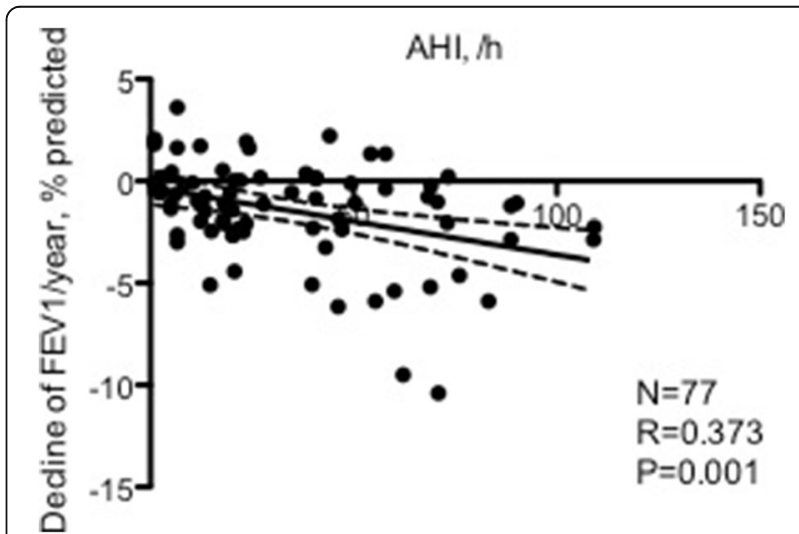

Fig. 2 Correlation between the apnoea-hypopnoea index (AHI) and the decline of $\mathrm{FEV}_{1}$ per year, \% predicted 
Table 4 Multivariate stepwise analysis of variables associated with the average decline of FEV1, \% predicted

\begin{tabular}{llclr}
\hline Parameter & beta & Standard error & $95 \% \mathrm{Cl}$ & $p$ value \\
\hline AHI & -0.033 & 0.009 & -0.052 to -0.014 & 0.001 \\
\hline
\end{tabular}

Abbreviations: $A H I$ apnoea-hypopnoea index, $O D I$ oxygen desaturation index $E R$ emergency department

function among asthmatics [23, 24]. Similarly, the results of present study also reveal that the number of ER visits is associated the decline in $\mathrm{FEV}_{1}$. For asthma control, the presence of OSA is associated with more symptoms, exacerbations and worse quality of life. Furthermore, CPAP treatment can alleviate the symptoms, the frequency of exacerbations and improve the quality of life [9-12]. Therefore, the decline of $\mathrm{FEV}_{1}$ may be alleviated by CPAP treatment in asthmatic patients with OSA. This is the first study reporting more exacerbations in asthmatic patients with OSA than in patients without OSA based on sleep lab population. In addition, CPAP treatment can reduce exacerbations in asthmatic patients with OSA. Such exacerbation is also associated with the decline in pulmonary function among asthmatic patients with OSA.

Inhaled corticosteroid (ICS) can alleviate the decline of $\mathrm{FEV}_{1}$ [22]. In addition, asthmatic patients with obesity are poor response to ICS [25]. The National Heart Lung and Blood Institute-sponsored Severe Asthma Research Program (SARP) has identified and characterized a phenotype of severe asthma consisting mainly of non-atopic lateonset older women with the highest body mass index, who are poor responders to ICS and frequently require oral corticosteroid use to manage exacerbations (Cluster 3). [26] Obesity is frequently associated with OSA. Therefore, asthmatic patients with OSA may also be poor responders to ICS, leading to accelerate the decline of $\mathrm{FEV}_{1}$. Another possible reason responsible to $\mathrm{FEV}_{1}$ decline due to obesity is that obesity may reduce $\mathrm{FEV}_{1}$ and FVC concurrently.

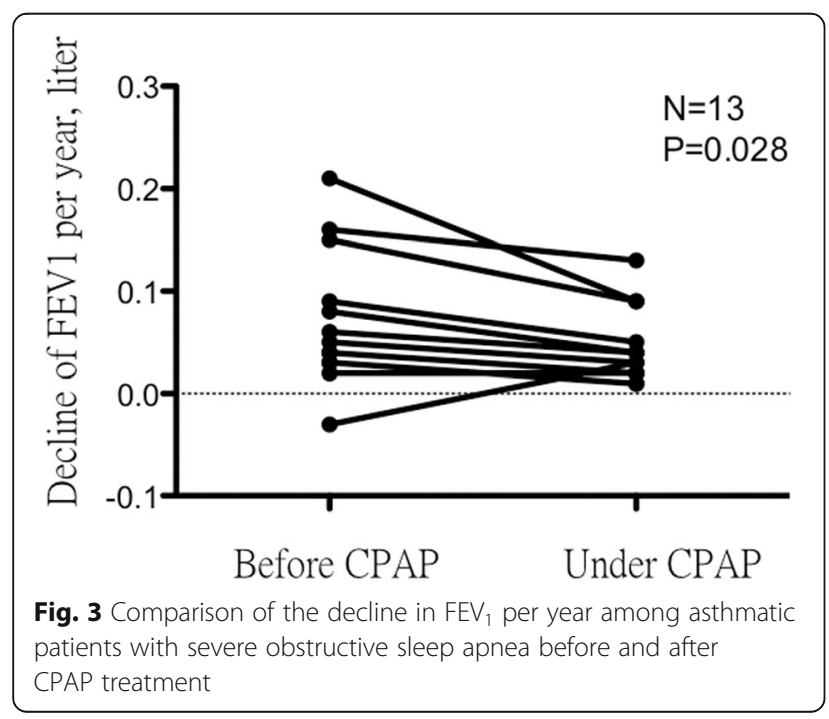

However, this study reveals that the baseline $\mathrm{FEV}_{1}$ is not significantly different between groups and there is trend in FVC, which is worse in severe OSA group. Therefore, obesity did not reduce $\mathrm{FEV}_{1}$ and $\mathrm{FVC}$ concurrently in this study. Furthermore, BMI is not significant associated with the decline of $\mathrm{FEV}_{1}$ in univariate analysis. Therefore, obesity is not a significant factor associated with the decline of $\mathrm{FEV}_{1}$ in asthmatic patients with OSA.

The major limitations of the present study include its retrospective nature, which may lead to bias in patient selection, and a relatively small sample size that may lead to spurious associations and conclusions. Proinflammatory profiles of asthma, such as FeNO, sputum or peripheral eosinophil counts were not entirely measured in every study subject in this retrospective study. A long-term, prospective study with a larger scale study is needed to corroborate these findings, and include the pro-inflammatory profiles into analysis for the association with annual decline in pulmonary function.

\section{Conclusions}

In conclusion, in a sample of the sleep-laboratory population, asthmatic patients with OSA have a substantially greater decline in $\mathrm{FEV}_{1}$ in 5-year follow-up compared to those without OSA. The impact of OSA on the annual decline in $\mathrm{FEV}_{1}$ is dose dependent. Moreover, CPAP treatment alleviates the decline in $\mathrm{FEV}_{1}$ among asthmatic patients with severe OSA.

\section{Abbreviations}

AHI: Apnoea-hypopnoea index; BMI: Body mass index; CPAP: Continuous positive airway pressure; ER: Emergency department; $\mathrm{FEV}_{1}$ : Forced expiratory volume in 1 second; FVC: Forced vital capacity; ODI: Oxygenation desaturation index; OSA: Obstructive sleep apnoea; REM: Rapid eye movement

\section{Acknowledgements}

This study was supported by a research grant from the Ministry of Science and Technology, Taiwan (103-2314-B-182A-097), Chang Gung Memorial Hospital,

Taiwan (CMRPG3F0461) and St. Paul's Hospital, Taiwan (SPMRP-U1-5006)

\section{Funding}

This study was supported by a research grant from the Ministry of Science and Technology, Taiwan (103-2314-B-182A-097; NMRPG3D0381), Chang Gung Memorial Hospital, Taiwan (CMRPG3F0461) and St. Paul's Hospital, Taiwan (SPMRP-U1-5006). The funders had no role in the design of this study nor the collection, analysis, and interpretation of data nor in the writing of this manuscript.

\section{Availability of data and materials}

The data that support the findings of this study are available from Chang Gung Memorial Hospital but restrictions apply to the availability of these data, which were used under license for the current study, and so are not publicly available. Data are however available from the authors upon reasonable request and with permission of Chang Gung Memorial Hospital.

\section{Authors' contributions}

TrW contributed to conceptualization and design of this study, collection, analysis, and interpretation of the data and preparation of the manuscript. YLL collection, analysis, and interpretation of the data; SML, CDH, FTC, CHW, $\mathrm{HCL}$ contributed to collection, analysis, and interpretation of the data; HPK contributed to conceptualization and design of the study interpretation of the data and preparation of the manuscript. All authors read and approved the final manuscript. 


\section{Competing interests}

None of the authors have a conflict of interest to declare in relation to this work.

\section{Consent for publication}

Not applicable.

\section{Ethics approval and consent to participate}

The Chang Gung Medical Foundation Institutional Review Board (103-1609B) approved the study and waived the requirement for informed consent due to the retrospective nature of this study.

\section{Publisher's Note}

Springer Nature remains neutral with regard to jurisdictional claims in published maps and institutional affiliations.

\section{Author details}

'Pulmonary Disease Research Centre, Department of Thoracic Medicine, Chang Gung Memorial Hospital, Chang Gung University, School of Medicine, 199 Tun-Hwa N. Rd., Taipei, Taiwan. ${ }^{2}$ Department of Thoracic Medicine, St. Paul's Hospital, Taoyuan, Taiwan.

Received: 1 October 2016 Accepted: 16 March 2017

Published online: 21 March 2017

\section{References}

1. Silverstein MD, Reed CE, O'Connell EJ, Melton 3rd LJ, O'Fallon WM Yunginger JW. Long-term survival of a cohort of community residents with asthma. N Engl J Med. 1994;331:1537-41.

2. Lange P, Ulrik CS, Vestbo J, Copenhagen City Heart Study Group. Mortality in adults with self-reported asthma. Lancet. 1996;347:1285-9.

3. Huovinen E, Kaprio J, Vesterinen E, Koskenvuo M. Mortality of adults with asthma: a prospective cohort study. Thorax. 1997:52:49-54.

4. Baek KJ, Cho JY, Rosenthal P, Alexander LE, Nizet V, Broide DH. Hypoxia potentiates allergen induction of HIF-1alpha, chemokines, airway inflammation, TGF-beta1, and airway remodeling in a mouse model. Clin Immunol. 2013:147:27-37.

5. Matsunaga K, Akamatsu K, Miyatake A, Ichinose M. Natural history and risk factors of obstructive changes over a 10-year period in severe asthma. Respir Med. 2013;107:355-60.

6. Lange P, Parner J, Vestbo J, Schnohr P, Jensen G. A 15-year follow-up study of ventilatory function in adults with asthma. N Engl J Med. 1998;339:1194-200.

7. Chan CS, Woolcock AJ, Sullivan CE. Nocturnal asthma: role of snoring and obstructive sleep apnea. Am Rev Respir Dis. 1988:137:1502-4.

8. Teodorescu M, Polomis DA, Hall SV, Teodorescu MC, Gangnon RE, Peterson AG, et al. Association of obstructive sleep apnea risk with asthma control in adults. Chest. 2010;138:543-50

9. Ekici A, Ekici M, Kurtipek E, Keles H, Kara T, Tunckol M, et al. Association of asthma-related symptoms with snoring and apnea and effect on health-related quality of life. Chest. 2005;128:3358-63.

10. Ciftci TU, Ciftci B, Guven SF, Kokturk O, Turktas H. Effect of nasal continuous positive airway pressure in uncontrolled nocturnal asthmatic patients with obstructive sleep apnea syndrome. Respir Med. 2005;99:529-34.

11. Ten Brinke A, Sterk PJ, Masclee AA, Spinhoven P, Schmidt JT, Zwinderman $\mathrm{AH}$, et al. Risk factors of frequent exacerbations in difficult-to-treat asthma. Eur Respir J. 2005;26:812-8

12. Lafond C, Series F, Lemiere C. Impact of CPAP on asthmatic patients with obstructive sleep apnoea. Eur Respir J. 2007;29:307-11.

13. Guilleminault C, Quera-Salva MA, Powell N, Riley R, Romaker A, Partinen M, et al. Nocturnal asthma: snoring, small pharynx and nasal CPAP. Eur Respir J. 1988;1:902-7.

14. Standards for the diagnosis and care of patients with chronic obstructive pulmonary disease (COPD) and asthma. This official statement of the American Thoracic Society was adopted by the ATS Board of Directors, November 1986. Am Rev Respir Dis. 1987;136:225-44.

15. Bateman ED, Hurd SS, Barnes PJ, Bousquet J, Drazen JM, FitzGerald M, et al. Global strategy for asthma management and prevention: GINA executive summary. Eur Respir J. 2008:31:143-78.

16. EEG arousals: scoring rules and examples: a preliminary report from the Sleep Disorders Atlas Task Force of the American Sleep Disorders Association. Sleep. 1992; 15:173-84.
17. Berry RB, Budhiraja R, Gottlieb DJ, Gozal D, Iber C, Kapur VK, et al. Rules for scoring respiratory events in sleep: update of the 2007 AASM Manual for the Scoring of Sleep and Associated Events. Deliberations of the Sleep Apnea Definitions Task Force of the American Academy of Sleep Medicine. J Clin Sleep Med. 2012;8:597-619.

18. Sleep-related breathing disorders in adults: recommendations for syndrome definition and measurement techniques in clinical research. The Report of an American Academy of Sleep Medicine Task Force. Sleep. 1999; 22:667-89.

19. Kushida CA, Chediak A, Berry RB, Brown LK, Gozal D, Iber C, et al. Clinical guidelines for the manual titration of positive airway pressure in patients with obstructive sleep apnea. J Clin Sleep Med. 2008:4:157-71.

20. Ulrik CS, Lange P. Decline of lung function in adults with bronchial asthma. Am J Respir Crit Care Med. 1994;150:629-34.

21. Cibella F, Cuttitta G, Bellia V, Bucchieri S, D'Anna S, Guerrera D, et al. Lung function decline in bronchial asthma. Chest. 2002;122:1944-8.

22. Dijkstra A, Vonk JM, Jongepier H, Koppelman GH, Schouten JP, Ten Hacken NH, et al. Lung function decline in asthma: association with inhaled corticosteroids, smoking and sex. Thorax. 2006;61:105-10.

23. Bai TR, Vonk JM, Postma DS, Boezen HM. Severe exacerbations predict excess lung function decline in asthma. Eur Respir J. 2007;30:452-6.

24. O'Byrne PM, Pedersen S, Lamm CJ, Tan WC, Busse WW, Group SI. Severe exacerbations and decline in lung function in asthma. Am J Respir Crit Care Med. 2009;179:19-24

25. Sutherland ER, Lehman EB, Teodorescu M, Wechsler ME, National Heart L. Blood Institute's Asthma Clinical Research N. Body mass index and phenotype in subjects with mild-to-moderate persistent asthma. J Allergy Clin Immunol. 2009:123:1328-34 e1.

26. Moore WC, Meyers DA, Wenzel SE, Teague WG, Li H, Li X, et al. Identification of asthma phenotypes using cluster analysis in the Severe Asthma Research Program. Am J Respir Crit Care Med. 2010;181:315-23.

\section{Submit your next manuscript to BioMed Central and we will help you at every step:}

- We accept pre-submission inquiries

- Our selector tool helps you to find the most relevant journal

- We provide round the clock customer support

- Convenient online submission

- Thorough peer review

- Inclusion in PubMed and all major indexing services

- Maximum visibility for your research

Submit your manuscript at www.biomedcentral.com/submit
Biomed Central 